\title{
Multigene assays: the changing paradigm of personalized medicine in breast cancer
}

\author{
Abbreviations: ER, endocrine receptor; TNBC, triple negative \\ breast cancer; FFPE, formalin-fixed paraffin-embedded; PCR, \\ polymerase chain reaction; NGS, next generation sequencing
}

\section{Introduction}

Worldwide, Breast cancer is a major public health issue with an estimated $6.6 \%$ of cases diagnosed in young women below the age of $40 .{ }^{1}$ It is the most commonly diagnosed cancer and leading cause of cancer mortality among women. ${ }^{2}$ It is estimated that over 522,000 women died due to breast cancer in $2012 .^{3}$ Breast cancer is a progressive disease ${ }^{4}$ with early stage exhibiting small tumors, negative axillary nodes, successful treatment and a better prognosis. Intriguingly, breast cancer in young women is associated with adverse pathological factors, hormone receptor negativity, and HER2 (human epidermal growth factor receptor overexpression which explains worse outcome. ${ }^{1}$ The screening and diagnosis of breast cancer patients at earlier stages benefits the patient, and also minimizes the financial burden. $^{5}$

The traditional clinical approach to treat both the in situ and invasive breast cancer involves the use of surgical, chemical and radiation based therapies. ${ }^{6}$ The decision as to whether to have further chemotherapy that includes drugs such as Cyclophosphamide, 5-fluorouracil, carboplatin, taxane and anthracycline can cause considerable distress and common side effects such as anemia, nausea, vomiting, fertility issues, memory loss, menopause and menopausal problems, neuropathy, fatigue and hair loss - can be a difficult one.? In general, chemotherapy damages cells that are dividing, so the parts of the body such as mouth, intestines, skin, hair, and bone marrow where normal cells divide frequently are likely to be affected by chemotherapy. Most therapies which are administered to treat breast cancer are quiet toxic so it is better to select and use suitable therapy for the appropriate women. Some side effects of chemotherapy are less common but more serious medical conditions that need to be treated. These include osteoporosis, heart problems and eye/vision problems. The limitations of chemotherapy, especially the narrow therapeutic index and the lack of discrimination for cancerous and non-cancerous cells have prompted the search for a greater target-directed approach to cancer treatment. Long-term side effects of chemotherapy could include damage to the heart, kidneys, lungs, nerves or reproductive organs. There is also a chance of developing a second cancer as a result of chemotherapy. ${ }^{8}$

Personalized medicine is a medical model where stratification of patients is done into pre-identified categories to guide better-informed treatment decisions, practices and interventions based on both the patients' clinical-pathological factors (age, tumor size, tumor grade, lymph node involvement, and hormone receptor status) and their underlying molecular conditions. For most solid tumors including breast cancer, surgery remains the main part of the treatment protocol. ${ }^{9}$ For many patients with early stage breast cancer, their risk of recurrence is not zero but is small. Evidence from large randomized trials and from large systematic reviews/meta-analyses such as EBCTCG (Early Breast Cancer Trialists' Collaborative Group) have shown that

\author{
Volume 4 Issue 4 - 2017
}

\author{
Girish Gaur \\ Department of Molecular Diagnostics, Diagno Labs India Private \\ Limited, India
}

\begin{abstract}
Correspondence: Girish Gaur, Department of Molecular Diagnostics, Diagno Labs India Private Limited, India,Tel +919718673331, Email dr.girish@diagnolabs.co.in
\end{abstract}

Received: August 04, 2017| Published: October 13, 2017

adjuvant chemotherapy, the difficult yet indispensable tool in cancer treatment substantially improves disease free and overall survival in all categories of breast cancers. ${ }^{10,11}$ However, with conventional treatment modalities, it also became evident that many patients relapse after treatment and many who qualified for established treatment protocols received no benefit from the treatment. ${ }^{12}$ An estimated three out of every four patients receiving this therapy would have survived without it. ${ }^{13,14}$ Pathological examination has been the gold standard for diagnosis in breast cancer and its role has also included the elucidation of etiology, pathogenesis, clinico-pathological correlation, and prognostication. ${ }^{15,16}$ Tumor grading is based on the level of cellular differentiation or resemblance to its normal counterpart. The introduction of less invasive techniques to obtain smaller specimens of the diseased tissue for examination and the improvement in the microscopic techniques refined the prediction of tumor behavior which itself became strongly focused on microscopic features. ${ }^{17}$ Microscopic features such as cell type, extent of differentiation, mitotic activity, microscopic lymph vascular invasion, lymphoplasmacytic reaction, metastasis, and the nature of the tumor borders also help in the better prediction of tumor behavior. The advent of newer technologies and the realization that breast cancer is a heterogeneous disease ${ }^{15}$ has shifted the focus to prognostication, with increased attention being paid to the identification of morphological features and immunohistochemical markers of prognostic relevance. The last five decades have seen a lot of transformation in the laboratory and clinical investigation and various surrogate molecular biomarkers such as ER (estrogen-receptor), PR (progesterone-receptor), Her2/neu, and Ki67 have been identified. These biomarkers have shown great promise in augmenting the standard methods of assessing the disease status and in determining the best treatment option for breast cancer patients. ${ }^{18,19}$

Despite all these advancements in the field of breast cancer, the strongest predictors for metastasis fail to classify accurately breast tumors according to their clinical behavior. The biology of each tumor is different and not all patients need to go through the difficult and challenging chemotherapy after a surgical procedure to kill chances of cancerous cells recurring. ${ }^{20}$ The likelihood of the cancer returning is based on several factors, including the size and "grade" of the tumor, and whether it has spread locally to the lymph nodes. In addition to patient preferences and comorbidities, the clinical management of early stage and potentially curable breast cancer includes the use of several different clinical and molecular characteristics of the tumor 
to formulate therapeutic recommendations. The prognostic and predictive strength of different markers is variable as they represent different distribution patterns and are quantified with unreliable accuracy. Age, tumor size and Ki67 expression represent continuous variables whereas histological grade and nodal status are ordinal variables. The ER and PR expression are variables with a bimodal distribution whereas HER2 gene amplification results are binary variables. Tumor size measurements in many pathology labs tend to be rounded off to the nearest number. Morphologically similar subtypes of breast cancer show molecular heterogeneity and based on over expression and under expression patterns of some molecular markers, breast carcinoma can be segregated into at least 4 molecular subtypes which are designated as luminal (ER+, PR+, and Her2/neu-), Her2 over expressing (ER-, PR-, and Her2/neu+), basal-like (ER-, PR-, Her2/neu-, and CK5/6+, EGFR+), and normal breast-like (ER-, PR-, and Her2/neu-), with each of these correlated to remarkably different clinical outcomes. ${ }^{11}$ When multiple factors measured with variable accuracy are associated with an outcome, the most precise predictions can only be achieved by multivariate prediction models. This gave birth to multivariate prognostic models such as Adjuvant Online and multi gene predictors. A great need exists for the better molecular characterization of tumor tissue in order to uncover the particular molecular alterations driving the tumor and multi gene assays provide credible information that assist in decision-making process, facilitate treatment selection, and ultimately improve patient outcomes. Multi gene prognostic assays are now endorsed by the American Society of Clinical Oncology (ASCO), St. Gallen, The National Institute for Health and Care Excellence (NICE) and National Comprehensive Cancer Network (NCCN) guidelines as actionable information achieved from these could assist in therapeutic decision making in ER-positive cancers.

\section{Multigene assays (Prognostic and predictive biomarkers)}

Last few years, have seen the development of several multi gene tests for risk assessment in early breast cancer to optimize the treatment and avoid unnecessary chemotherapy. These tests evaluate the genes which are involved in critical molecular pathways involved in the breast cancer metastatic cascade and are able to analyze molecular subtypes of the cancer, risk of recurrence of early stage cancer, thereby enabling medical oncologists in identifying the benefit of chemotherapy in addition to the endocrine treatment in node-negative early breast cancer. Multiple genomic assays are currently in use for breast cancer which include IHC4, Onco type DX, Mamma Print, Blue Print, PAM50, Endo predict, Mammo strat, Mamma Typer, Genomic Grade Index and Breast cancer Index (Table 1). While most of these assays are primarily prognostic in nature, but still there are differences in their approach to achieve the same: The immunohistochemical $4(\mathrm{IHC} 4)$ score is a pathological prognostic score that is a quantitative measurement of ER, PR, the HER2/neu receptor and the Ki-67 gene. ${ }^{21}$ A detailed study of 1125 ER-positive lymph node-negative breast cancer patient samples from Trans ATAC cohort, IHC4 along with a clinical treatment score has been shown to provide similar amounts of prognostic information to that provided by the 21 -gene recurrence score of Onco type DX, in patients determined to be at intermediate risk of recurrence using standard clinical variables. ${ }^{22}$ IHC4 uses a mathematical formula that weighs the semi quantitative expression values. However, in the absence of standardized quantification of each of the four variables, IHC4 scores determined from the 2 different methodologies correlated moderately therefore applying the formula to local pathology results could be highly misleading. ${ }^{23,24}$ One of the recently published study for validation of IHC4 algorithm on the 2919 samples of TEAM (Tamoxifen Versus Exemestane Adjuvant Multicenter Trial) cohort for predicting residual risk in patients with breast cancer also supported the role of IHC4 algorithm clinically, but emphasized that quantitative and standardized approaches need to be used..$^{25}$ The role of the IHC4 score in predicting local recurrence is still evolving. The four markers ER/PR/HER2 and Ki-67 used in combination to derive the IHC4 also display independent significance in the prognosis of breast cancer.

Table I IHC4, Onco type DX, Mamma Print, Blue Print, PAM50, Endo predict, Mammo strat, Mamma Typer, Genomic Grade Index and Breast cancer Index

\begin{tabular}{|c|c|c|c|c|c|}
\hline Test & Assay type & Intended use & Sample & Technology & Outcome \\
\hline $\mathrm{IHC} 4$ & Prognostic test & $\begin{array}{l}\text { Any invasive, primary, ER-positive } \\
\text { tumors }\end{array}$ & FFPE & IHC (4 IHC markers) & $\begin{array}{l}\text { Risk score and category (low risk } \\
\text { vs. high risk) }\end{array}$ \\
\hline $\begin{array}{l}\text { Onco type } \\
\text { DX }\end{array}$ & $\begin{array}{l}\text { Prognostic and } \\
\text { Predictive test }\end{array}$ & ER-positive, node-negative disease & FFPE & qRT-PCR ( 16 genes) & $\begin{array}{l}\text { Risk score and category (high vs. } \\
\text { moderate vs. low risk) }\end{array}$ \\
\hline $\begin{array}{l}\text { Mamma } \\
\text { Print }\end{array}$ & $\begin{array}{l}\text { Prognostic and } \\
\text { Predictive test }\end{array}$ & $\begin{array}{l}\text { Invasive breast cancer, pT I-2, } \\
\text { pN0-3, age }<61 \text { years }\end{array}$ & $\begin{array}{l}\text { Fresh/frozen } \\
\text { or FFPE }\end{array}$ & $\begin{array}{l}\text { DNA microarrays ( } 70 \\
\text { genes) }\end{array}$ & $\begin{array}{l}\text { Risk category (low risk vs. high } \\
\text { risk) }\end{array}$ \\
\hline Blue Print & Intrinsic subtypes & $\begin{array}{l}\text { Invasive breast cancer, pT I-2, } \\
\text { pN0-3, age }<61 \text { years }\end{array}$ & $\begin{array}{l}\text { fresh/frozen } \\
\text { or FFPE }\end{array}$ & $\begin{array}{l}\text { DNA microarrays ( } 80 \\
\text { genes) }\end{array}$ & Intrinsic subtype \\
\hline PAM50 & $\begin{array}{l}\text { Prognostic test, } \\
\text { intrinsic subtypes }\end{array}$ & $\begin{array}{l}\text { Invasive breast cancer, regardless } \\
\text { of stage or ER status }\end{array}$ & FFPE & $\begin{array}{l}\text { Nanostring nCounter } \\
\text { (50 genes) }\end{array}$ & $\begin{array}{l}\text { Intrinsic subtype, risk of } \\
\text { recurrence score (continuous) }\end{array}$ \\
\hline Endopredict & Prognostic test & ER-positive, HER2-negative disease & FFPE & qRT-PCR ( 12 genes) & $\begin{array}{l}\text { Risk score and category (low risk } \\
\text { vs. high risk) }\end{array}$ \\
\hline Mammostrat & Prognostic test & $\begin{array}{l}\text { ER-positive, lymph node-negative } \\
\text { tumors treated with tamoxifen }\end{array}$ & FFPE & IHC (5 IHC markers) & $\begin{array}{l}\text { Risk category (high vs. moderate } \\
\text { vs. low risk) }\end{array}$ \\
\hline $\begin{array}{l}\text { Mamma } \\
\text { Typer }\end{array}$ & Intrinsic subtypes & $\begin{array}{l}\text { Invasive breast cancer, regardless } \\
\text { of stage or ER status }\end{array}$ & FFPE & qRT-PCR (4 genes) & Intrinsic subtype \\
\hline $\begin{array}{l}\text { Breast } \\
\text { Cancer } \\
\text { Index }\end{array}$ & Prognostic test & ER-positive, node-negative disease & FFPE & qRT-PCR ( 5 genes $)$ & $\begin{array}{l}\text { Risk score and category (low risk } \\
\text { vs. high risk) }\end{array}$ \\
\hline
\end{tabular}


Table Continued...

\begin{tabular}{|c|c|c|c|c|c|}
\hline Test & Assay type & Intended use & Sample & Technology & Outcome \\
\hline $\begin{array}{l}\text { Genomic } \\
\text { Grade Index }\end{array}$ & Prognostic test & $\begin{array}{l}\text { Any invasive, primary, ER-positive, } \\
\text { grade } 2 \text { tumors }\end{array}$ & FFPE & $\begin{array}{l}\text { DNA microarrays ( } 97 \\
\text { genes) or qRT-PCR ( } 4 \\
\text { genes) }\end{array}$ & $\begin{array}{l}\text { Risk category (low risk vs. high } \\
\text { risk) }\end{array}$ \\
\hline $\begin{array}{l}\text { Germ Line } \\
\text { BRCA } \\
\text { mutation }\end{array}$ & Predictive test & TNBC & $\begin{array}{l}\text { Fresh/frozen } \\
\text { or FFPE }\end{array}$ & $\begin{array}{l}\text { Sanger sequencing/NGS } \\
\text { ( } 2 \text { genes) }\end{array}$ & $\begin{array}{l}\text { Predict sensitivity to PARP } \\
\text { inhibitors }\end{array}$ \\
\hline $\begin{array}{l}\text { Foundation } \\
\text { one }\end{array}$ & Predictive test & Primary/metastatic & $\begin{array}{l}\text { Fresh/frozen } \\
\text { or FFPE }\end{array}$ & NGS (>300 genes) & $\begin{array}{l}\text { Molecular target profiling for use } \\
\text { of targeted drugs }\end{array}$ \\
\hline
\end{tabular}

\section{ER and PR}

The ER/PR status has been shown to have a significant predictive value on tumor response to hormonal therapy in both the metastatic as well as for adjuvant therapy after local excision but their prognostic value is still a case of debate. ${ }^{12,26}$ Clinical data suggest that tamoxifen is less efficacious in ER+ PR- tumors than in ER+ PR+ tumors. ${ }^{27}$ Studies also suggest that ER- PR+ tumors have poorer prognosis than $\mathrm{ER}+\mathrm{PR}+$ tumors. ${ }^{28}$ However, due to the rarity of ER- PR+ breast cancer (incidence: $1.5-3.4 \%$ ), the characteristics and prognosis of this tumor are not well known.

\section{HER2/neu}

HER2/neu, is an important transmembrane protein and a member of epidermal growth factor receptor family. It is involved in critical signaling pathways that control cell proliferation and survival and has been shown to be a poor prognostic marker and its overexpression has been associated with worse overall survival. ${ }^{29,30}$ In addition to its prognostic role, overexpression/amplification of HER2/neu in patients with breast carcinoma has been shown to be associated with an increased sensitivity to doxorubicin-based therapies ${ }^{31,32} \mathrm{Ki}-67$ : Ki67 is a proliferation marker and high levels of Ki-67 are associated with HER2/-neu positivity. ${ }^{33}$ The International $\mathrm{Ki}-67$ in Breast Cancer Group of the Breast International Group and North American Breast Cancer Group (BIG-NABCG) has created guidelines for the assessment of $\mathrm{Ki}-67$ with recommendations on pre-analytical and analytical procedures, as well as on interpretation, scoring, and data handling. ${ }^{34}$ However, it is still not recommended in routine pathological evaluation because it is not totally clear how Ki-67 measurements and thresholds could influence clinical decisions. ${ }^{35,36}$ Available data also indicate prognostic value of Ki-67 is influenced by the number of positive lymph nodes. Breast cancer patients with 1-3 positive axillary lymph nodes and $>25 \%$ Ki-67 positive cells had significantly worse metastasis free survival and overall survival. ${ }^{37}$

Onco type DX test uses RT-PCR technology to analyze the activity of 21 genes and then calculates and categorizes patients into Low, Intermediate, High risk based on a continuous risk score number between 0 and 100; the higher the score, the greater the risk of recurrence. It is used to estimate a woman's risk of recurrence in early-stage, hormone-receptor-positive breast cancer. Onco type DX has been shown to predict the magnitude of chemotherapy benefit in tamoxifen-treated patients in the NSABP B20 trial. ${ }^{38}$ Multiple clinical trials such as NSABP B-14, ${ }^{39}$ NSABP B-20, ${ }^{38}$ Trans ATAC ${ }^{40}$ and $\mathrm{SWOG}^{41}$ have determined that the Recurrence Score is also associated with the likelihood of chemotherapy benefit in node-positive patients. All these studies concluded that a recurrence score result $<18$ predicted little to no benefit from chemotherapy, while a score $\geq 31$ predicted a larger benefit from chemotherapy. Some prospective trials such as TAILORx are underway where 10253 node-negative, ER-

positive, HER2-negative patients were enrolled at 1182 sites in six countries from April 2006 to October 2010. The initial results have shown less than $1 \%$ risk of distant recurrence at five years in patients with recurrence Score results $<11$ who were treated with hormonal therapy alone.

Mamma Print is a prognostic and predictive diagnostic assay based on a 70 gene signature that assesses the risk of a tumor to metastasize to other parts of the body. Mamma Print test is used to estimate a women's recurrence risk for early-stage breast cancer as well as how likely she is to benefit from chemotherapy after breast cancer surgery. The 70 gene signature is shown to have independent prognostic values over clinical-pathological risk assessment in breast cancer patients. The assay is performed using an Agilent microarray system and is used for Early stage breast cancer (stage I and II), irrespective of ER, PR and HER2 status. The assay has also been validated on patients who have up to 3 positive lymph nodes. The RNA extracted from the tissue section is hybridized to a customized microarray which then calculates either a high-risk or a low-risk recurrence score. A retrospective clinical trial conducted by TRANSBIG consortium, validated and proved the clinical utility of the assay. The data suggests a significant difference in risk of recurrence (ROR) between the patients categorized as low risk and high risk by Mamma print test. ${ }^{42}$ A prospective randomized control evaluation of a breast cancer prognosis signature to prove the performance of the assay was conducted on 427 patients (T1-3N0M0) under the RASTER (microarRAy-prognoSTics-in-breast-cancER) study. $97 \%$ of the MammaPrint identified Low Risk patient group, which primarily chose to forego chemotherapy, were disease free after 5 years. The study concluded that omission of adjuvant chemotherapy as judged appropriate by doctors and patients and instigated by a lowrisk 70-gene signature result, appeared not to compromise outcome..$^{43}$ Another large scale prospective, randomized, phase III, controlled clinical trial; MINDACT was initiated to investigate the clinical utility of MammaPrint, when compared to (or used in conjunction with) standard clinical pathological criteria, for the selection of patients unlikely to benefit from adjuvant chemotherapy. From 2007 to 2011, 6693 women across 112 centers in nine countries, who had undergone surgery for early-stage breast cancer, were enrolled in the trial. The preliminary results indicate that Mamma Print can help reduce overtreatment of breast cancer patients by $46 \%$, even in the presence of high risk clinical features. ${ }^{44-46}$ In addition to this a companion test called Blu Print uses the expression patterns of 80 genes and categorizes the tumors into intrinsic subtypes i.e. luminal, basal and HER2/neu type tumors. ${ }^{46}$ Patients with HER2+/Luminal A disease seem to have a relative better outcome compared to the other subtypes. On the other hand HER2+/HER2-enriched tumors seem to benefit the most from trastuzumab, or dual HER2 blockade with trastuzumab/lapatinib, in combination with chemotherapy. Overall, data suggests that intrinsic molecular profiling provides clinically relevant information beyond current pathology-based classifications. 


\section{PAM50}

The Prosigna breast cancer prognostic gene signature assay employs nCounter system from Nano String. It is a genomic test that analyzes the expression profiles for 50 genes and classifies tumors into four intrinsic subtypes (luminal A, luminal B, HER2-enriched, and basal-like). It categorizes the patients into three risk groups and provides a continuous risk score. Prosigna proved its clinical validity through TransATAC and ABCSG- 8 trials with a cumulative validation pool of $>2400$ post-menopausal women with early-stage, hormone receptor-positive breast cancer who received 5years of endocrine therapy after surgical resection of the primary tumor. The data from two studies suggests a significant correlation of Prosigna ROR to 10year distant recurrence $(\mathrm{P}<0.0001)$. The low-risk group had a 10 -year risk of distant recurrence of $<5 \%$, while the high-risk group had a 10 year risk of distant recurrence of $>20 \%$ in node-negative patients. ${ }^{47-50}$ Breast Cancer Index (BCI) is a prognostic tool which uses an RTPCR platform and is based on the expression levels of 5 genes which include HOX B13/IL17BR ratio that categorizes the ER positive and lymph node negative patients into high risk and low risk categories. $\mathrm{BCI}$ has shown significant prognostic performance over 10years for the prediction of individual risk of distant recurrence for hormone receptor-positive N0 patients in the TransATAC cohort. ${ }^{51}$ By default physicians tend to recommend extended endocrine therapy, consistent with ASCO guidelines and randomized clinical trial results. ${ }^{52} \mathrm{BCI}$ identifies early-stage estrogen receptor-positive breast cancer patients at risk for early- and late-distant recurrence and assists in taking a calculated decision for an extended endocrine therapy; extend or end endocrine therapy at year 5 and beyond.

Endo Predict test measures the levels of 12 genes using an RT-PCR platform in early-stage, hormone-receptor-positive, HER2-negative breast cancer patients, with up to three positive nodes. Data from patients randomized within the prospective ABCSG- 8 trial proved Endo Predict to be an effective prognostic tool for identifying risk of local recurrence in postmenopausal endocrine receptor-positive, her2neu-negative breast cancer. ${ }^{53}$ These expression level patterns of the 12 genes in conjunction with cancer tumor size and the nodal status of the cancer are used to calculate an EPclin risk score that classifies the cancer as having a high risk or a low risk of the cancer metastasizing to an area of the body away from the breast. EP and EPclin were found to be highly prognostic across the 10years of follow-up and both scores also identified early and late relapse events in the TransATAC population study. ${ }^{54}$ These results were in agreement with previous reports in ER-positive, HER2-negative patient cohorts from the ABCSG-6 and -8 trials. ${ }^{55,56}$ Mammostrat is a 5-protein IHC based prognostic assay that assesses 5 functional proteins - SLC7A5, p53, HTF9C, NDRG1, and CEA-CAM5. This assay was validated in 2 trials, NSABP B14 and B20 (same used for Onco type DX) that included 711 cases of node negative and ER+ patients. The assay gives low, moderate, and high risk readout. ${ }^{57}$ Mammostrat was further evaluated in the TEAM trial with a total of 3837 cases. The results suggest an independent impact on 10-year distant recurrence-free survival over and above size, grade, nodal status and ER/PR/HER2 status. ${ }^{58}$

\section{Next generation sequencing}

Breast cancer is a heterogeneous disease and the cellular and molecular diversity between and within tumors as well as among cancer-bearing individuals is very high. ${ }^{59,60} \mathrm{In}$ fact, recent data on tumor heterogeneity and cancer cells' dynamic mutations throughout time have shown that one biopsy is insufficient to fully explore the complexity of a tumor. ${ }^{61}$ The distinct biological, molecular, and clinical factors play an important role in determining the risk of disease progression and therapeutic resistance. Most of the breast cancer cases are sporadic, but 5 to $10 \%$ of all breast cancer cases show a specific inheritance pattern. BRCA1 and BRCA2 genes are the most commonly implicated genes in familial breast cancer and are responsible for up to $40 \%$ of all inherited breast cancer cases. ${ }^{62}$ Other genes such as CDH1, TP53, PTEN, STK11, FANCA, PALB2, BRIP1, RAD51C, XRCC2, ATM, CHEK2, NBN, RAD50, RAD51B, and RAD51D have also been found to increase susceptibility to breast cancer. $^{63}$

Another challenging category in breast cancer is the triplenegative breast cancer (TNBC), as defined by tumors that lack estrogen receptor, progesterone receptor and human epidermal growth factor receptor 2 (HER2) overexpression. This specific group accounts for approximately $15-20 \%$ of all breast cancer types. ${ }^{64}$ Almost all TNBCs are of basal-like molecular subtype and they share similarities with BRCA-1 associated breast cancer that include deficiency in DNA-repairing pathways. Approximately half of all TNBC reach pathological complete remission (pCR) upon neoadjuvant chemotherapy. A substantial amount of preclinical data suggests the many TNBC harbor DNA repair deficiencies, and therefore drugs that induce DNA damage may be particularly effective. There may be hundreds of different mutations associated with resistance to standard chemotherapy and that is the reason why overall comparison of groups of sensitive versus resistant tumors does not lead to candidate markers. ${ }^{65}$ Functional BRCA1/2 are crucial for repair of double-strand breaks through homologous DNA repair mechanism in which the homologous sequence is used to precisely repair the break. In patients with mutated or nonfunctional BRCA, Poly (adenosine diphosphate-ribose) polymerases (PARPs) dependent base excision repair pathway becomes vital to cells defective in homologous recombination. Therefore, in such tumor cells PARP inhibition leads to persistent double-strand breaks and this in turn induces apoptosis. ${ }^{66}$ Next Generation sequencing (NGS), has allowed us to analyze sequences from such challenging tumors and helped us find new treatment targets. Many new mutations and several important signaling pathways have been identified. However the biggest challenge is that no two tumors have the same molecular makeup and hence the same driving mutations. This leads us to the fact that there are many different molecular mechanisms which are responsible for tumorigenesis and each tumor is unique in its tumor causing molecular events. A central premise behind cancer target profiling is that tumors that share the same driver mutation will respond to a corresponding targeted drug regardless of histologic subtype whereas cancers without the mutation will not.

\section{Conclusion}

Over the time, it has become apparent that breast cancer is not a single type of tumor, but a group of different diseases with distinct molecular properties. Each of these molecularly different breast cancer types tends to respond differently (or not at all) to the various kinds of available therapy. As discussed previously ER/PR and HER2 status are subjective to pathologist's evaluation, hence a great need exists for better molecular characterization of tumor tissue. Determining the functional molecular sub typing based on the quantitative RNA expression of genes involved in the downstream pathways of ER, PR, HER2, and Ki-67 will enable us to accurately characterize the tumors based on the functional pathways which are involved in the growth 
of tumor. This would provide additional information about the tumor biology and help to facilitate the appropriate treatment selection. American Joint Commission on Cancer (AJCC) has also considered the need and adoption of non-anatomical prognostic factors based on the biological behavior of cancers in addition to the TNM extent of disease to identify and counsel patients on prognosis and treatment options hormone receptor-positive/HER2-negative and lymph nodenegative breast cancer patients with a low-risk recurrence score of multigene breast cancer prognostic panels, such as Onco type DX, Mamma print, Endo Predict, PAM 50, and Breast Cancer Index, should be considered as same prognostic category as T1a-T1b N0 M0 tumors, regardless of tumor size. ${ }^{67}$

Likewise microRNAs demonstrates a potential biomarker as these have been shown to be consistently upregulated and downregulated and have been shown to possess predictive and prognostic values. Many of these microRNAs have been linked to the currently used biomarkers in breast cancer management. But there are multiple concerns as far as microRNAs are concerned. The most important being the issue of normalization of the microRNAs, and the problem of reproducibility of these results across different labs.

No doubt that the quantification of ER, PR and HER2 are being increasingly standardized and inter-laboratory reproducibility has improved substantially over the past fewyears. However, multigene signatures introduced an important concept into the need for multivariate prediction models. The introduction of molecular techniques such as $\mathrm{CGH}$ arrays, proteomics profiling and sequencing technology and the development of other high throughput technologies have opened up new avenues of exploration into the genesis of breast cancer. More importantly it has led to the realization that there are potentially new and specifically tailored avenues of treatment. Pathologists continue to play their traditional role in diagnosis but, as purveyors of the excised tissue, they now have the additional role of identifying biomarkers responsive to therapeutic manipulation, thus playing an inextricable role as diagnostic oncologists in the management of breast cancer. Such developments have defined a new role for the pathologist paving the Way for Personalized Medicine in a New Era.

\section{Acknowledgements}

None.

\section{Conflict of interest}

The author declares no conflict of interest.

\section{References}

1. Assi HA, Khoury KE, Dbouk H, et al. Epidemiology and prognosis of breast cancer in young women. J Thorac Dis. 2003;5 Suppl 1:S2-S8.

2. Siegel RL, Miller KD, Jemal A. Cancer statistics. CA Cancer J Clin. 2016;66(1):7-30.

3. Ferlay J, Soerjomataram I, Ervik M, et al. GLOBOCAN 2012: Cancer Incidence and Mortality Worldwide. France: (IARC) International Agency for Research on Cancer; 2013.

4. Chang J, Yang WT, Choo HF. Mammography in Asian patients with BRCA1 mutations. Lancet. 1999;353(9169):2070-2071.

5. Onitilo AA, Engel JM, Liang H, et al. Mammography utilization: patient characteristics and breast cancer stage at diagnosis. AJR Am J Roentgenol. 2013;201(5):1057-1063.
6. Zoon CK, Starker EQ, Wilson AM, et al. Current molecular diagnostics of breast cancer and the potential incorporation of microRNA. Expert Rev Mol Diagn. 2009;9(5):455-467.

7. Early Breast Cancer Trialists' Collaborative Group (EBCTCG). Effects of chemotherapy and hormonal therapy for early breast cancer on recurrence and 15-year survival: an overview of the randomized trials. Lancet. 2005;365(9472):1687-1717.

8. Calip GS, Malmgren JA, Lee WJ, et al. Myelodysplastic syndrome and acute myeloid leukemia following adjuvant chemotherapy with and without granulocyte colony-stimulating factors for breast cancer. Breast Cancer Res Treat. 2015;154(1):133-143.

9. Forget P, Simonet O, De Kock M. Cancer surgery induces inflammation, immunosuppression and neo-angiogenesis, but is it influenced by analgesics? F1000 Res. 2013;2:102.

10. Tesarova P. Breast cancer in the elderly-Should it be treated differently? Rep Pract Oncol Radiother. 2012;18(1):26-33.

11. Early Breast Cancer Trialists' Collaborative Group (EBCTCG), Peto R, Davies C, Godwin J, et al. Comparisons between different polychemotherapy regimens for early breast cancer: meta-analyses of long-term outcome among 100,000 women in 123 randomized trials. Lancet. 2012;379(9814):432-444.

12. Leong AS, Zhuang Z. The changing role of pathology in breast cancer diagnosis and treatment. Pathobiology. 2011;78(2):99-114.

13. Polychemotherapy for early breast cancer: an overview of the randomised trials. Early Breast Cancer Trialists' Collaborative Group. Lancet. 1998;352(9132):930-942.

14. Tamoxifen for early breast cancer: an overview of the randomised trials. Early Breast Cancer Trialists' Collaborative Group. Lancet. 1998;351(9114):1451-1467.

15. Leong AS, Zhuang Z. The changing role of pathology in breast cancer diagnosis and treatment. Pathobiology. 2011;78(2):99-114.

16. Elmore JG, Longton GM, Carney PA, et al. Diagnostic concordance among pathologists interpreting breast biopsy specimens. JAMA. 2015;313(11):1122-1132.

17. Deisboeck TS, Wang Z, Macklin P, et al. Multiscale cancer modeling. Annu Rev Biomed Eng. 2011;13:127-155.

18. Malhotra GK, Zhao X, Band $\mathrm{H}$, et al. Histological, molecular and functional subtypes of breast cancers. Cancer Biol Ther. 2010;10(10):955-960.

19. Ahmad A. Pathways to breast cancer recurrence. ISRN Oncol. 2013;2013(2013):1-16.

20. Laura J, Hongyue Dai, Marc J van de Vijver, et al. Gene expression profiling predicts clinical outcome of breast cancer. Nature. 2002;415(6871):530-536.

21. Barton S, Zabaglo L, A'Hern R, et al. Assessment of the contribution of the IHC4+C score to decision making in clinical practice in early breast cancer. Br J Cancer. 2012;106(11):1760-1765.

22. Cuzick J, Dowsett M, Pineda S, et al. Prognostic value of a combined estrogen receptor, progesterone receptor, $\mathrm{Ki}-67$, and human epidermal growth factor receptor 2 immunohistochemical score and comparison with the Genomic Health recurrence score in early breast cancer. J Clin Oncol. 2011;29(32):4273-4278.

23. Győrffy B, Hatzis C, Sanft T, et al. Multigene prognostic tests in breast cancer: past, present future. Breast Cancer Res. 2015;17(1):11.

24. Peck AR, Girondo MA, Liu C, et al. Validation of tumor protein marker quantification by two independent automated immunofluorescence image analysis platforms. Mod Pathol. 2016;29(10):1143-1154. 
25. Bartlett JM, Christiansen J, Gustavson M, et al. Validation of the IHC4 Breast Cancer Prognostic Algorithm Using Multiple Approaches on the Multinational TEAM Clinical Trial. Arch Pathol Lab Med. 2016;140(1):66-74.

26. Rastelli F, Crispino S. Factors predictive of response to hormone therapy in breast cancer. Tumori. 2008;94(3):370-383.

27. Bardou VJ, Arpino G, Elledge RM, et al. Progesterone receptor status significantly improves outcome prediction over estrogen receptor status alone for adjuvant endocrine therapy in two large breast cancer databases. J Clin Oncol. 2003;21(10):1973-1979.

28. Rakha EA, El-Sayed ME, Green AR, et al. Biologic and clinical characteristics of breast cancer with single hormone receptor positive phenotype. J Clin Oncol. 2007;25(30):4772-4778.

29. Iqbal N, Iqbal N. Human Epidermal Growth Factor Receptor 2 (HER2) in Cancers: Overexpression and Therapeutic Implications. Mol Biol Int. 2014;2014:852748.

30. English DP, Roque DM, Santin AD. HER2 expression beyond breast cancer: therapeutic implications for gynecologic malignancies. Mol Diagn Ther. 2013;17(2):85-99.

31. Villman K, Sjöström J, Heikkilä R, et al. TOP2A and HER2 gene amplification as predictors of response to anthracycline treatment in breast cancer. Acta Oncol. 2006;45(5):590-596.

32. Slamon DJ, Press MF. Alterations in the TOP2A and HER2 genes: association with adjuvant anthracycline sensitivity in human breast cancers. J Natl Cancer Inst. 2009;101(9):615-618.

33. Inwald EC, Klinkhammer-Schalke M, Hofstädter F, et al. Ki-67 is a prognostic parameter in breast cancer patients: results of a large population-based cohort of a cancer registry. Breast Cancer Res Treat. 2013;139(2):539-552.

34. Klintman M, Dowsett M. Early Surrogate Markers of Treatment Activity: Where Are We Now? J Natl Cancer Inst Monogr. 2015;2015(51):24-28.

35. Polley MY, Leung SC, McShane LM, et al. An international Ki67 reproducibility study. J Natl Cancer Inst. 2013;105:1897-1906.

36. Ács B, Zámbó V, Vízkeleti L, et al. Ki-67 as a controversial predictive and prognostic marker in breast cancer patients treated with neoadjuvant chemotherapy. Diagn Pathol. 2017;12(1):20.

37. Li FY, Wu SG, Zhou J, et al. Prognostic value of Ki-67 in breast cancer patients with positive axillary lymph nodes: a retrospective cohort study. PLoS One. 2014;9(2):e87264.

38. Paik S, Tang G, Shak S, et al. Gene expression and benefit of chemotherapy in women with node-negative, estrogen receptor-positive breast cancer. J Clin Oncol. 2006;24(23):3726-3734.

39. Paik S, Shak S, Tang G, et al. A multigene assay to predict recurrence of tamoxifen-treated, node-negative breast cancer. $N$ Engl J Med. 2004;351(27):2817-2826

40. Sestak I, Cuzick J, Dowsett M, et al. Prediction of late distant recurrence after 5years of endocrine treatment: a combined analysis of patients from the Austrian breast and colorectal cancer study group 8 and arimidex, tamoxifen alone or in combination randomized trials using the PAM50 risk of recurrence score. J Clin Oncol. 2015;33(8):916-922.

41. Albain KS, Barlow WE, Shak S, et al. Prognostic and predictive value of the 21-gene recurrence score assay in postmenopausal women with node-positive, oestrogen-receptor-positive breast cancer on chemotherapy: a retrospective analysis of a randomised trial. Lancet Oncol. 2010;11(1):55-65.

42. Buyse M, Loi S, van't Veer L, et al. Validation and clinical utility of a 70 gene prognostic signature for women with node-negative breast cancer. $J$ Natl Cancer Inst. 2006;98(17):1183-1192.
43. Drukker CA, Bueno-de-Mesquita JM, Retèl VP, et al. A prospective evaluation of a breast cancer prognosis signature in the observational RASTER study. Int J Cancer. 2013;133(4):929-936.

44. Viale G, de Snoo FA, Slaets L, et al. Immunohistochemical versus molecular (BluePrint and MammaPrint) subtyping of breast carcinoma Outcome results from the EORTC 10041/BIG 3-04 MINDACT trial. Breast Cancer Res Treat. 2018;167(1):123-131.

45. Aalders KC, Kuijer A, Straver ME, et al. Characterisation of multifocal breast cancer using the 70-gene signature in clinical low-risk patients enrolled in the EORTC 10041/BIG 03-04 MINDACT trial. Eur $J$ Cancer. 2017;79:98-105.

46. Cardoso F, van't Veer LJ, Bogaerts J, et al. 70-Gene Signature as an Aid to Treatment Decisions in Early-Stage Breast Cancer. $N$ Engl J Med. 2016;375(8):717-729.

47. Dowsett M, Sestak I, Lopez-Knowles E, et al. Comparison of PAM50 risk of recurrence score with Oncotype DX and IHC4 for predicting risk of distant recurrence after endocrine therapy. $J$ Clin Oncol. 2013;31(22):2783-2790.

48. Dowsett M, Cuzick J, Wale C, et al. Prediction of risk of distant recurrence using the 21-gene recurrence score in node-negative and node-positive postmenopausal patients with breast cancer treated with anastrozole or tamoxifen: a TransATAC study. J Clin Oncol. 2010;28(11):1829-1834.

49. Dubsky PC, Jakesz R, Mlineritsch B, et al. Tamoxifen and anastrozole as a sequencing strategy: a randomized controlled trial in postmenopausal patients with endocrine-responsive early breast cancer from the Austrian Breast and Colorectal Cancer Study Group. J Clin Oncol. 2012;30(7):722-728.

50. Gnant M, Filipits M, Greil R, et al. Austrian Breast and Colorectal Cancer Study Group. Predicting distant recurrence in receptor-positive breast cancer patients with limited clinicopathological risk: using the PAM50 Risk of Recurrence score in 1478 postmenopausal patients of the ABCSG-8 trial treated with adjuvant endocrine therapy alone. Ann Oncol. 2014;25(2):339-345.

51. Sgroi DC, Sestak I, Cuzick J, et al. Prediction of late distant recurrence in patients with oestrogen-receptor-positive breast cancer: a prospective comparison of the breast-cancer index (BCI) assay, 21-gene recurrence score, and IHC4 in the TransATAC study population. Lancet Oncol. 2013;14(11):1067-1076.

52. Myrick ME, Schmid SM, Kilic N, et al. Eligibility, compliance and persistence of extended adjuvant endocrine therapy for breast cancer. Acta Oncol. 2012;51(2):247-253.

53. Fitzal F, Filipits M, Rudas M, et al. The genomic expression tes EndoPredict is a prognostic tool for identifying risk of local recurrence in postmenopausal endocrine receptor-positive, her2neu-negative breast cancer patients randomised within the prospective ABCSG 8 trial. $\mathrm{Br} J$ Cancer. 2015;112(8):1405-1410.

54. Buus R, Sestak I, Kronenwett R. Comparison of EndoPredict and EPclin With Oncotype DX Recurrence Score for Prediction of Risk of Distant Recurrence After Endocrine Therapy. J Natl Cancer Inst. 2016:108(11).

55. Filipits M, Rudas M, Jakesz R, et al. A new molecular predictor of distant recurrence in ER-positive, HER2-negative breast cancer adds independent information to conventional clinical risk factors. Clin Cancer Res. 2011;17(18):6012-6020.

56. Dubsky P, Brase JC, Jakesz R, et al. The EndoPredict score provides prognostic information on late distant metastases in ER+/HER2- breast cancer patients. Br J Cancer. 2013;109(12):2959-2964.

57. Ross DT, Kim CY, Tang G, et al. Chemosensitivity and stratification by a five monoclonal antibody immunohistochemistry test in the NSABP B14 and B20 trials. Clin Cancer Res. 2008;14(20):6602-6609. 
58. Bartlett JM, Bloom KJ, Piper T, et al. Mammostrat as an immunohistochemical multigene assay for prediction of early relapse risk in the tamoxifen versus exemestane adjuvant multicenter trial pathology study. J Clin Oncol. 2012;30(36):4477-4484.

59. Polyak K. Heterogeneity in breast cancer. $J$ Clin Invest. 2011;121(10):3786-3788.

60. Beca F, Polyak K. Intratumor Heterogeneity in Breast Cancer. Adv Exp Med Biol. 2016;882:169-189.

61. Aparicio S, Caldas C. The implications of clonal genome evolution for cancer medicine. $N$ Engl J Med. 2013;368(9):842-851.

62. Melchor L, Benítez J. The complex genetic landscape of familial breast cancer. Hum Genet. 2013;132(8):845-863.

63. Jalkh N, Chouery E, Haidar Z, et al. Next-generation sequencing in familial breast cancer patients from Lebanon. BMC Med Genomics. 2017;10(1):8
64. Bauer KR, Brown M, Cress RD, et al. Descriptive analysis of estrogen receptor (ER)-negative, progesterone receptor (PR)-negative, and HER2-negative invasive breast cancer, the so-called triple-negative phenotype: a population-based study from the California cancer Registry. Cancer. 2007;109(9):1721-1728.

65. Borst P, Wessels L. Do predictive signatures really predict response to cancer chemotherapy? Cell Cycle. 2010;9(24):4836-4840.

66. Arnedos M, Bihan C, Delaloge S, et al. Triple-negative breast cancer: are we making headway at least? Ther Adv Med Oncol. 2012;4(4):195-210.

67. Orucevic A, Bell JL, McNabb AP, et al. Oncotype DX breast cancer recurrence score can be predicted with a novel nomogram using clinicopathologic data. Breast Cancer Res Treat. 2017;163(1):51-61. 